\title{
Bus driver accident record; stability over time, exposure and culpability
}

\author{
Anders E. af Wåhlberg* \\ A.E.Af-Wahlberg@cranfield.ac.uk \\ $+44-1234758225$ \\ \& \\ Lisa Dorn \\ 1.dorn@cranfield.ac.uk \\ +44-1234 758229 \\ School of Aerospace, Transport and Manufacturing, \\ Cranfield University, Cranfield, Bedfordshire, MK43 0AL \\ UK \\ * corresponding author
}

\begin{abstract}
The tendency for drivers to have a stable accident record over time was tested in a population of bus drivers. Analyses included investigations of the effects of responsibility for the crash, exposure and length of time period, on stability. All associations between numbers of accidents for individuals in different short time periods were found to be weak, but longer time periods increased the size of the correlations.

Restricting the analyses to include only those crashes for which the drivers were deemed responsible had a slightly negative effect on correlations. However, this was due to lower means (and thus variance) in these calculations. Similarly, controlling for hours worked decreased the correlations somewhat, but this was due to an outlier problem. The results are consistent with previous research and indicate that stability of accident involvement exists and that the effects can be reliably found under certain methodological circumstances. The sizes of coefficients are determined mainly by the restriction of variance, not by any underlying lack of stability. The stable tendency to cause mishaps within the same environment is a strong factor in traffic safety although this is not apparent when variance in the data is low.
\end{abstract}

Keywords: bus driver; traffic accident; crash; exposure; culpability

\section{Relevance to Human Factors/Ergonomics Theory}

It has been claimed that involvement in accidents is not stable within individuals over time or environments. This paper reports results which counter these claims. The question of whether people are stable over time in their accident-causing behaviours is fundamental to human factors, and need more research. 


\section{Introduction}

In the early days of safety research, it was noted that the number of accidents for a worker or a driver tended to correlate between time periods and different activities (Greenwood \& Woods, 1919). Such stability across domains and time indicates some sort of innate or learned behaviour tendency. Over the next sixty years more than thirty papers published coefficients on the size of this effect (reviewed and meta-analysed in af Wåhlberg, 2009). However, critics pointed to the fact that effect sizes were rather small (e.g. Arbous \& Kerrich, 1951; Harrington, 1972; Maycock, 1985) and interest in the concept of stability decreased for a while. In the last twenty years, another dozen or so papers have reported coefficients for this effect for drivers (e.g. Cantor, Corsi, Grimm \& Özpolat, 2010; Chandraratna, 2004; Elliott, Waller, Raghunathan \& Shope, 2001; Elliott, Waller, Raghunathan, Shope \& Little, 2000; Goh, Currie, Sarvi, \& Logan, 2014; Klauer, Dingus, Neale, Sudweeks \& Ramsey, 2009; Ma, Yan, Huang \& Abdel-Aty, 2010; af Wåhlberg \& Dorn, 2009; Visser, Pijl, Stolk, Neeleman \& Rosmalen, 2007; Summala, Rajalin \& Radun, 2014; Wundersitz, 2008). In general, all these publications agree that a positive correlation between previous and future traffic accidents can be seen. However, the reported effect sizes are often rather weak, similar to earlier results. One possible explanation for this is that the cited studies have often suffered from various methodological shortcomings, which have probably influenced the effect sizes. Using meta-analysis, it has been shown that the number of traffic accident involvements (per person) correlate between time periods. The strength of these correlations is determined by the variation in the data (af Wåhlberg, 2009). Low correlations between time periods are thus simply due to restriction of variance, a statistical artefact. Using longer time periods and high-risk populations yield higher means and variances and therefore also larger correlation coefficients (af Wåhlberg, 2009; af Wåhlberg \& Dorn, 2009).

Another factor that might increase the strength of association between accidents of different time periods is that of culpability. The logic here is that incidents for which the drivers are not to blame are random occurrences (Chandraratna, 2004) that can only be predicted by their exposure, not by previous behaviour (accidents). This is an assumption of the quasi-induced exposure method, where non-culpable accidents are used as a proxy for actual exposure (Carr, 1969, Haight, 1973). Therefore, theoretically, including nonculpable accidents in a dependent variable will only add error variance. Omitting nonculpable accidents should lead to stronger correlations between time periods. The leftover, non-culpable accidents should only correlate between time periods to a maximum degree of the association of exposure between periods (Dorn \& af Wåhlberg, 2018; af Wåhlberg, 2009; 2018; af Wåhlberg \& Dorn, 2007). However, the drop in variation from deleting some incidents could counter this positive effect, and a strict test of this hypothesis would therefore need a comparison between correlations in populations with similar means, or a statistical control (as in af Wåhlberg, Barraclough \& Freeman, 2016). In agreement with this statement, the between-time periods correlations for crash involvement have been shown to increase at a faster rate with the mean of crashes for culpable crashes (as meta-analysed in af Wåhlberg, 2009). This happens despite culpability in these studies probably being less than optimally coded with the use of police officers and company official accounts. No objective test of the correctness of 
coding is undertaken, although this is possible to do (Dorn \& af Wåhlberg, 2018; af Wåhlberg, 2018).

Exposure is also a potential confounding variable in calculations on accident record stability, as highly exposed drivers should have more accidents than those less exposed to risk. If differences in exposure tend to be stable over time, they will create stability in accident record which is not due to how the drivers drive. It is indeed commonly found within traffic research that exposure and number of accidents are positively associated, although weakly and not linearly (e.g. Liddell, 1982; Maycock, 1995; Peck, 1993, but see also the analysis in af Wåhlberg, 2009; 2011). Somewhat strangely, exposure has rarely been taken into account in studies on stability of accident record (af Wåhlberg, 2009), but controlling for it could potentially reduce effect sizes further.

However, exposure to risk of a traffic accident can be conceptualized and measured in several different ways; by mileage (McCartt, Shabanova \& Leaf, 2003), by actual time driving (Kaneko \& Jovanis, 1992), by time working (Blom, Pokorny \& van Leeuwen, 1987) by time as licence holder or employee (Cornwall, 1962), by induced exposure (Clarke, Ward, Bartle \& Truman, 2006) or combinations of these (Dorn \& af Wåhlberg, 2008). These methodological choices probably to some degree determine the results (Chipman, MacGregor, Smiley \& Lee-Gosselin, 1992; 1993).

Yet another aspect of correlations between accident involvement in different time periods concern the time between data sets (variables). Usually, the association between one time period and the period directly after the first time period is reported. However, Milosevic and Vucinic (1975) showed that the association tended to decrease when time periods that were longer apart where correlated. Such an effect would make sense, as various environmental factors would be able to influence the accident involvement of people differently over time.

A strict analysis of the stability of accident involvement over time would therefore need to include holding exposure constant and comparing effects of culpable accidents to all accidents while holding the mean (number of accidents) in the sample constant. In summary, the aim of the present study was to investigate the stability in individual traffic accident record over different time periods, including the effect of using culpable accidents only and computing the differences when using accidents per year and per hour of driving per year. The novelty in the present study lies in the high quality of the culpability coding method compared with previous studies as well as the exact and highly reliable measure of exposure.

The only previous study known to have undertaken similar manipulations is Dorn and af Wåhlberg (submitted). However, in that study, exposure was held constant in a different way, by using full-time drivers only, and culpability was judged differently (Dorn \& af Wåhlberg, 2018). It is possible that other studies have also held exposure constant by using full-time drivers only, but these may still differ due to sick leave etc. The current study is therefore the most precise investigation reported so far into the factors of exposure and culpability in relation to the stability of accident involvement. 


\section{Method}

\subsection{General}

Data on drivers was available from the bus company Gamla Uppsalabuss (GUB) in Uppsala, Sweden. This company run all intra-city bus routes (between 40 and 50 at any one time) of Uppsala, a town of about 200000 inhabitants. With a few exceptions, buses are either 12 or 18 meters (articulated) long. The majority of GUB drivers drive on dozens of different routes. In a single day, they drive two or three routes, and these are usually not driven again within the next few days. The only exception to this rule is the night route drivers, but those are less than five percent of the total, and usually also work occasional day shifts. Most routes are fairly similar in terms of the types of neighbourhoods they pass through; typically the routes start in residential areas on the outskirts of Uppsala, pass through the city centre and end up in a similar area on the other side of town. This makes the drivers' risk exposure very homogeneous.

\subsection{Accident data}

Crash data was retrieved from the database of bus driver accidents at GUB described in af Wåhlberg (2002a; 2004). This source contains most accidents that have happened, 1986-2005. The company require that drivers report all kinds of mishaps and check the buses daily for damage (af Wåhlberg, 2002a). The database has also been found to contain more accidents than the drivers can retrospectively self-report over a period of three years (af Wåhlberg, 2002b). There is therefore likely to be a high correspondence between this database and the actual number of accidents taking place (at least from 1994 and onwards as some earlier files appear to have been lost).

In this database, all reported incidents resulting in vehicle damage (apart from paint scratches only) have been included. Also included are injuries (bloodshed or need for medical care) to both passengers and other road users (af Wåhlberg, 2002a). Accident culpability was coded by the first author on three different levels, but for the present study it was dichotomized into none versus at least some responsibility. The criterion used to decide on culpability was that the driver should have been unable to avoid the accident by behaving differently (see further af Wåhlberg, 2002a; af Wåhlberg \& Dorn, 2007). About one third of all bus driver incidents were judged as non-culpable (see Table 1). Other data gathered from the bus company was age, sex, experience (years of employment), and number of hours worked each year from 1999 to 2003, for each driver.

\subsection{Samples}

As the population of drivers at GUB changes continuously and rather quickly, the choice of time periods had to be weighed against the available $\mathrm{N}$ (number of drivers). A long time period would have very few drivers who had worked throughout the period being investigated. However, it was possible to extract two only slightly overlapping samples from the database. The first sample could be used for aggregation of accident data over a longer time period (eight years), while the second one (eight years) could be used for comparing years and number of hours at work as units of exposure. Exposure data, in terms of hours worked, were not available for the first sample, while both samples had culpability data. A third sample could be formed from the other two, with an even longer time period (twelve years), but with a smaller $\mathrm{N}$. 
Table 1 shows that the bus driver samples used were somewhat older and worked more hours per year than the total population of drivers. Also, the drivers in the samples by necessity differed from the others on the variable of length of time of employment. Of some interest is the fact that the mean number of crashes per year was much lower for the later time periods, which is consistent with a general decrease in crashes in the population during this time period (about four percent per year). Based on the low average number of hours worked (about 1600 hours would be full time) and the fairly large standard deviation of this value, it can be concluded that the company had many part-time drivers. Hours worked correlates 0.2 to 0.8 between years, with the stronger correlations coming from adjacent years.

Table 1 Descriptive statistics for demographic variables (2001-12-31) and crashes (for the total time period) of the samples and the population in 2001. Sex (percent men) and ethnic origin (percent Swedish) was determined from names.

\begin{tabular}{|l|l|l|l|l|l|l|l|l|}
\hline Group & N & Age & $\begin{array}{l}\text { Experien } \\
\text { ce }\end{array}$ & $\begin{array}{l}\text { Hours } \\
\text { worked }\end{array}$ & Sex & $\begin{array}{l}\text { Ethnic } \\
\text { origin }\end{array}$ & $\begin{array}{l}\text { Culpable } \\
\text { crashes }\end{array}$ & $\begin{array}{l}\text { All } \\
\text { crashes }\end{array}$ \\
\hline Sample 1 (8 y) & 180 & $50.5 / 8.5$ & $19.8 / 8.0$ & $1373 / 481$ & $86.7 \%$ & $81.7 \%$ & $2.14 / 2.11$ & $2.50 / 2.35$ \\
\hline Sample 2 (8 y) & 185 & $48.0 / 9.0$ & $14.1 / 9.6$ & $1495 / 433$ & $85.9 \%$ & $65.9 \%$ & $1.55 / 1.75$ & $2.27 / 2.13$ \\
\hline Sample 3 (12 y) & 133 & $50.4 / 8.0$ & $19.3 / 7.4$ & $1460 / 414$ & $84.2 \%$ & $80.5 \%$ & $2.32 / 2.20$ & $3.49 / 2.93$ \\
\hline Population (1 y) & 394 & $45.8 / 10.2$ & $10.5 / 10.3$ & $1257 / 581$ & $89.6 \%$ & $58.6 \%$ & $0.21 / 0.53$ & $0.30 / 0.62$ \\
\hline
\end{tabular}

\subsection{Analytical methods}

The choice of statistical method was mainly decided by the need to compare the results with previous research (see af Wåhlberg, 2009; 2010). Therefore, Pearson correlations were used. Although this method is not optimal for the somewhat skewed data used in the present paper, investigating the absolute size of coefficients was not the prime goal of this study. Instead, the relative size when the three chosen manipulations (length of time period, amount of exposure and culpability) were applied was the main focus. When association measures between accidents in different time periods were calculated, it was not obvious which periods should be paired. Most researchers tend to use consecutive years. However, when the goal is to study the (expected) change in correlation with aggregation over several years, the picture becomes a bit more complicated. In the present study, all possible comparisons were taken into account (i.e. first year correlated with second and third and so on) and the mean of those associations calculated. Otherwise, random occurrences (like differences in mean accident liability between years) could have effects and lead to under- or overestimations of correlations. This is especially the case for samples of the current size. When inter-correlations are averaged, such occurrences will tend to cancel each other out.

\section{Results}

\subsection{Age, experience and accidents}

Descriptive statistics for the three samples and the population of bus drivers at one point in time are displayed in Table 1, for age, experience (length of service with GUB), hours worked, sex, ethnic origin (Swedish/non-Swedish, determined from names), and crashes. Correlations between these variables are shown in Table 2. It can be noted that experience and ethnicity were more strongly associated with culpable crashes compared with all crashes, while the opposite was true for hours worked. This pattern could be 
expected from a correct coding of culpability (af Wåhlberg \& Dorn, 2007). The strong correlation between ethnic origin and experience means that drivers with typical Swedish names had a length of service that was three times longer than drivers with non-Swedish names.

Table 2 The intercorrelations between crash data and various demographic variables in the population data for 2001. $\mathrm{N}=407$

\begin{tabular}{|l|l|l|l|l|l|l|}
\hline Variable & Age & Experience & $\begin{array}{l}\text { Hours } \\
\text { worked }\end{array}$ & Sex & Ethnic origin & $\begin{array}{l}\text { Culpable } \\
\text { crashes }\end{array}$ \\
\hline Experience & $0.528^{* * *}$ & & & & & \\
\hline $\begin{array}{l}\text { Hours } \\
\text { worked }\end{array}$ & $0.117^{*}$ & $0.191^{* * *}$ & & & & \\
\hline Sex & -0.030 & 0.045 & 0.019 & & & \\
\hline Ethnic origin & $0.209^{* * *}$ & $0.428^{* * *}$ & -0.077 & $-0.241^{* * *}$ & & \\
\hline $\begin{array}{l}\text { Culpable } \\
\text { crashes }\end{array}$ & -0.053 & $-0.150^{* *}$ & 0.090 & 0.032 & $-0.185^{* * *}$ & \\
\hline All crashes & -0.044 & -0.103 & $0.123^{*}$ & 0.060 & $-0.163^{* * *}$ & $0.874 * * *$ \\
\hline
\end{tabular}

$* \mathrm{p}<.05, * * \mathrm{p}<.01, * * * \mathrm{p}<.001$

\subsection{Effects of length of time period}

It can be seen in Table 3 that the between time periods correlations increased with increased time periods (and therefore also higher means and standard deviations). Furthermore, one-year periods yielded correlations which differed a lot between each other, while two-year periods had associations which were much more similar (which can be seen by comparing the maximums and minimums).

Table 3 The average, maximum and minimum correlations between number of all crashes in different years (with the mean calculated as the square root of the mean of the squared correlations, with originally negative values subtracted from the mean).

\begin{tabular}{|c|c|c|c|c|c|}
\hline All accidents & Time period & Mean & Max & Min & $\mathrm{k}$ \\
\hline \multirow{3}{*}{$\begin{array}{l}\text { Sample 1, } \\
\text { 1994-2001, } \\
\mathrm{N}=180\end{array}$} & $1 \mathrm{x} 1$ years & 0.140 & 0.346 & -0.076 & 28 \\
\hline & $2 \times 2$ years & 0.203 & 0.295 & 0.133 & 6 \\
\hline & $4 \times 4$ years & 0.280 & - & - & 1 \\
\hline \multirow{3}{*}{$\begin{array}{l}\text { Sample 2, } \\
\text { 1999-2006, } \\
\mathrm{N}=185\end{array}$} & $1 \mathrm{x} 1$ years & 0.143 & 0.277 & -0.043 & 28 \\
\hline & $2 \times 2$ years & 0.194 & 0.261 & 0.117 & 6 \\
\hline & $4 \times 4$ years & 0.312 & - & - & 1 \\
\hline \multirow{4}{*}{$\begin{array}{l}\text { Sample 3, } \\
1994-2005, \\
N=133\end{array}$} & $1 \times 1$ years & 0.156 & 0.404 & -0.083 & 66 \\
\hline & $2 \times 2$ years & 0.208 & 0.431 & -0.033 & 15 \\
\hline & $3 \times 3$ years & 0.264 & 0.465 & 0.109 & 6 \\
\hline & $6 \times 6$ years & 0.408 & - & - & 1 \\
\hline
\end{tabular}

\subsection{Effects of culpability}

The next step was to investigate the correlations of culpable crashes. It can be seen in Table 4 that the correlations in eight out of ten cases were smaller than the corresponding results for all accidents (Table 3). However, this does not take into account the increase in restriction of variance when non-culpable crashes are deleted. 
Table 4 The average, maximum and minimum correlations between number of culpable crashes in different years (with the mean calculated as the square root of the mean of the squared correlations, with originally negative values subtracted from the mean).

\begin{tabular}{|c|c|c|c|c|c|}
\hline $\begin{array}{l}\text { Culpable } \\
\text { accidents }\end{array}$ & Time period & Mean & Max & Min & $\mathrm{k}$ \\
\hline \multirow{3}{*}{$\begin{array}{l}\text { Sample 1, } \\
\text { 1994-2001, } \\
\mathrm{N}=180\end{array}$} & $1 \mathrm{x} 1$ years & 0.128 & 0.330 & -0.032 & 28 \\
\hline & $2 \times 2$ years & 0.194 & 0.274 & 0.118 & 6 \\
\hline & $4 \times 4$ years & 0.258 & - & - & 1 \\
\hline \multirow{3}{*}{$\begin{array}{l}\text { Sample 2, } \\
\text { 1999-2006, } \\
\mathrm{N}=185\end{array}$} & $1 \mathrm{x} 1$ years & 0.139 & 0.335 & -0.044 & 28 \\
\hline & $2 \times 2$ years & 0.219 & 0.287 & 0.134 & 6 \\
\hline & $4 \times 4$ years & 0.347 & - & - & 1 \\
\hline \multirow{4}{*}{$\begin{array}{l}\text { Sample 3, } \\
1994-2005 \\
N=133\end{array}$} & $1 \mathrm{x} 1$ years & 0.120 & 0.331 & -0.131 & 66 \\
\hline & $2 \times 2$ years & 0.172 & 0.368 & -0.028 & 15 \\
\hline & $3 \times 3$ years & 0.224 & 0.393 & 0.058 & 6 \\
\hline & $6 \times 6$ years & 0.280 & - & - & 1 \\
\hline
\end{tabular}

\subsection{Effects of exposure}

To investigate the effects of exposure, the accidents for each year for sample 2 were divided by the number of hours each driver had worked that year. Three subjects were deleted, as they were extreme outliers on the accidents per hour parameter $(>5 \mathrm{std}$ above the mean), due to very few hours spent driving in combination with a crash. All correlations where exposure had been held constant were lower than the corresponding ones for accidents by years (see Table 5). However, an outlier problem was still apparent in these variables, and deleting ten more such cases would have increased the correlations until they were larger than their by-year counter-parts. This problem will be explored further in the discussion.

As an alternative, all drivers with less than 100 hours of driving $(\mathrm{N}=5)$ in any year were deleted from the sample ${ }^{1}$. The resulting correlations between years were a few percent smaller than those in Table 5.

Table 5 The average, maximum and minimum correlations between number of crashes per hours worked in different years (with the mean calculated as the square root of the mean of the squared correlations, with originally negative values subtracted from the mean). Three outliers (5 std) deleted.

\begin{tabular}{|l|l|l|l|l|l|}
\hline $\begin{array}{l}\text { Sample 2, } \\
1999-2006, \\
\text { N=182 }\end{array}$ & Time period & Mean & Max & Min & $\mathrm{k}$ \\
\hline \multirow{5}{*}{ All accidents } & 1x1 years & 0.130 & 0.241 & -0.060 & 28 \\
\cline { 2 - 7 } & $2 \times 2$ years & 0.161 & 0.200 & 0.127 & 6 \\
\cline { 2 - 7 } & 4x4 years & 0.269 & - & - & 1 \\
\hline \multirow{2}{*}{$\begin{array}{l}\text { Culpable } \\
\text { accidents }\end{array}$} & 1x1 years & 0.122 & 0.287 & -0.064 & 28 \\
\cline { 2 - 7 } & 2x2 years & 0.156 & 0.211 & 0.156 & 6 \\
\cline { 2 - 7 } & 4x4 years & 0.303 & - & - & 1 \\
\hline
\end{tabular}

\subsection{Effects of time distance between time periods}

To investigate whether the accident record correlations between time periods decreased when the periods were not adjacent, the correlations for one-year periods and the twoyear period for sample 3 in Tables 3 and 4 were correlated with the time in between time

\footnotetext{
${ }^{1}$ This method was suggested by an anonymous reviewer, which is gratefully acknowledged.
} 
periods (i.e. 1994/1995 would be zero, and 1997/2000 would be two). Seven out of eight meta-correlations were negative (Table 6). However, only two effects were significant.

Table 6 The meta-correlations between the correlation between crashes in two time periods and the time distance between the periods.

\begin{tabular}{|l|l|l|l|l|}
\hline Crashes & $\begin{array}{l}\text { Sample 1, 1 year } \\
(\mathrm{k}=28)\end{array}$ & $\begin{array}{l}\text { Sample 2, 1 year } \\
(\mathrm{k}=28)\end{array}$ & $\begin{array}{l}\text { Sample 3, 1 year } \\
(\mathrm{k}=66)\end{array}$ & $\begin{array}{l}\text { Sample 3, 2 } \\
\text { years, }(\mathrm{k}=15)\end{array}$ \\
\hline All & -0.098 & -0.002 & -0.163 & -0.230 \\
\hline Culpable & -0.330 & 0.223 & $-0.318^{* *}$ & -0.424 \\
\hline
\end{tabular}

$* * \mathrm{p}<.01$

\section{Discussion \\ 4.1 Results}

The present paper analyzed data concerning the stability over time of traffic accident involvement in three overlapping samples of bus drivers, with the effects of culpability and exposure taken into account. Coefficients increased with longer time periods (aggregation) but not with the use of culpable crashes or controlling for exposure. The results for between time periods correlations were somewhat or very much lower than most others reported for professional drivers (af Wåhlberg, 2009). Thus, at first look, the stability of accident record over time for GUB drivers would seem to be much lower than has been previously found for similar populations.

However, as noted in the introduction, meta-analysis of accident record stability shows that the size of a between time periods correlations is almost solely determined by the length of the time period used, the mean number of accidents in the population, and driver type (bus, tram, or car drivers). These three predictor variables had a fairly large degree of overlap, but the mean in isolation explained about eighty percent of the variation in between-time periods correlations. The results of a previous version of the present paper were included in that meta-analysis. They fit in well with other studies, given the mean number of accidents, the time periods used and the type of population used (af Wåhlberg, 2009).

Similarly, the use of culpable accidents seems to have had a slightly negative effect on the associations between time periods in the present data. However, as the mean of accidents decreased to $2 / 3 \mathrm{rds}$ of the original when non-culpable crashes were deleted, this difference is not easily interpreted. Given the association between the size of correlation and other variables described above, a fair comparison should be between culpable crashes and all crashes in another population, but with a similar mean. In the cited metaanalysis, culpable crashes generally had lower correlations than all crashes at very low means $(<0.14$ for the total time period), while outperforming all crashes at higher levels with the same mean. In the present data, in every comparison between all and culpable involvement correlations, the culpable crashes had about thirty percent lower means. It is therefore to be expected that the correlations for culpable crashes were lower.

It should be noted that the idea about a culpability category as a stability-enhancing factor is not new; Peck (1993) discussed and tested this, reporting results that were fairly similar to the ones reported here. The interpretation by Peck, however, was different, because he only looked at the size of the correlations, without taking into account the difference in variance. 
Holding exposure fairly constant by using accidents per hour had a slight effect on the correlations. This could be interpreted as evidence that some of the between time periods associations found were due to a stability in the amount of exposure, and not behaviour. However, the exposure results were hard to interpret, due to the outlier problem, which will be discussed in the next section.

\subsection{Limitations}

It is very rare for hours of driving to be used as a measure of exposure in studies on individual differences in safety. It is even more unusual to include part-time drivers and such extremely short time periods as one year. It has therefore not really been acknowledged that the combination of these factors can create extreme outliers. These outliers are very difficult to handle statistically, as they have a very strong influence on effects. Usually, the convention of two standard deviations is accepted as a criterion for a value being an outlier, and deleted from the data. In the present investigation, a very conservative criterion of five standard deviations was applied, and even this had a noticeable effect on the correlations. However, even with outliers included, the correlations between years increased with the time periods and became sizeable at the higher end. Thus, the principle of increasing stability with increasing time periods is apparent even when there is a severe statistical problem present. However, the outlier problem does limit the possibility of drawing conclusions from the present data.

Milosevic and Vucinic (1975) and Häkkinen (1958) claimed that associations waned with the lengthening of the time period between accident periods. This is a reasonable assumption, but the support provided in their data for this hypothesis was slight, as in the case of the present data. However, rather long periods of time are needed for such calculations to yield decisive evidence, as the number of effects included in a calculation will be rather small. Apparently, the current dataset was too small for this type of calculation.

In the present data, the criterion used for culpability could be erroneous and/or some of the reports from the drivers may have been biased. This may have led to a sizeable error component for the judgement of culpability. This would have the effect of suppressing any positive effect of using culpable crashes as a stability-enhancing method. However, the data used has been shown to conform to what could be expected theoretically, and it can be claimed that the criterion is fairly correct (af Wåhlberg \& Dorn, 2007; Dorn \& af Wåhlberg, 2018). In spite of this, judging culpability remains a problem which should be treated with caution.

The main statistical test used was the Pearson correlation, which has often been said not to be suitable for skewed data. Log transformations are recommended in order to decrease skewness. Such tests were run for the present data (and have been tried before on similar datasets), but yielded no difference in the results.

The data presented here is for bus drivers, and thus may not be representative for drivers of other types of vehicles, or for accidents of other types than road crashes. However, the results agree to a fair degree with those for car and tram drivers (af Wåhlberg, 2009). Finally, the samples used tended to be different from the population of drivers, as they were the ones who had stayed with the company. This is an unfortunate effect which is always present when professional drivers are studied. This can limit the applicability of the findings to other driver groups. 


\subsection{Methodology}

It can be noted that, in the present data, the correlations between crashes in different time periods increased when the periods were increased, even though there was a general decrease in average number of crashes per driver in the company. It should therefore be pointed out that the concept of stability of accident involvement allows for such a development. Here, the meaning of accident record stability is in reference to other individuals, not in an absolute sense. This will, for example, allow for the known effects of age and experience on safety.

In the present context, exposure was only considered in terms of amount (time, which for bus drivers is probably very similar to mileage), not quality. The latter was found by Häkkinen (1958) and McKenna, Duncan and Brown (1986) to have no discernible influence within bus driver populations. For the present study, GUB practice duty rotation so the possibility of stable differences in level of environmental risk exposure between drivers is considered negligible.

Regarding time as a unit of exposure, it should be noted that most researchers (but not all) use a basic form of constancy; accidents during a certain number of years, or per year, equal for all subjects. However, in the present study, this was not regarded as controlling for exposure, as the variation in terms of driving time and/or mileage may be very large between drivers within the same time period. Only for professional populations with all subjects working full time could this be considered adequate. On the other hand, it is possible that exposure should be controlled for in a non-linear way, and that this would achieve higher stability figures. However, the problem of the non-linear association between accidents and exposure has not really been solved within traffic psychology, and is largely ignored in individual accident prediction research today (af Wåhlberg, 2003; 2009).

We propose that the stability of accident involvement over time and environment is not explained by a single dimension of behaviour (for example, intentional risk-seeking, or clumsiness). Instead it can be caused by all kinds of behavioural mechanisms which contribute to accidents. Given such a construct, it is of some interest then to ask whether there are causes of crashes which cannot be included under the stability of accident record concept. This could also be phrased as a research question about whether there may be a definitive limit to the increasing between time periods coefficients. This has been discussed in af Wåhlberg (2009) in relation to an outlying effect size. It would seem probable that the increase is actually curvilinear, and stops short of explaining a hundred percent of the variance.

In the end, accident stability lends a different perspective to traffic safety, which in the light of the present findings, requires further exploration.

\subsection{Conclusions}

The current study has shown that exposure is not a stability-enhancing factor for accident record. It would seem to be the first study ever to have tested this hypothesis, although a forthcoming study show similar results (Dorn \& af Wåhlberg, submitted). Furthermore, the coefficients become rather impressive in size over long time periods. This means that for the purpose of predicting future crash involvement, previous crashes are a far stronger factor than most other variables found in the traffic safety literature (e.g. Arthur, Barrett 
\& Alexander, 1991; Barraclough, af Wåhlberg, Freeman, Watson \& Watson, 2016; Bioulac et al., 2017; Vaa, 2003; af Wåhlberg, Barraclough \& Freeman, 2016). Similarly, our understanding of risk tendencies in traffic should be enhanced if we acknowledge that crash records are, in a relative sense, stable over decades.

Individual differences in the sense of stable behaviour differences over time and environments are accepted as existing for almost any kind of human action (e.g. Szalma, 2009). This includes several variables assumed to be important for safety, such as stress (Matthews \& Campbell, 2009), navigational strategy (Baldwin, 2009), and locus of control (Smith \& Iskra-Golec, 2003). But if there exist stable individual differences in safety behaviour (de Winter, 2014), this must have as a result that accident record is stable over time. This, however, has been denied by many researchers, whether they accept individual differences as such (e.g. McKenna, 1983), or take a systems approach and claim that 'all animals are equal' (e.g. Thoroman, Goode $\&$ Salmon, 2018). This denial of stable individual differences in accident record is blatantly gainsaid by the current results.

Finally, some recommendations concerning future research on the topic of the stability of accident record over time can be given. The problem of exposure would seem to be the most important one to solve. Here, basic research about the best measure of exposure to traffic accident risk is needed. Thereafter, studies using an improved exposure measure could estimate this influence on stability. Furthermore, studies on populations of road users such as motorcyclists, and pedestrians, are lacking. Considering stability in diverse groups could indicate whether we are in fact dealing with a general personality trait, or something more particular.

\section{References}

Arbous, A. G., \& Kerrich, J. E. (1951). Accident statistics and the concept of accident proneness. Biometrics, 7, 340-432.

Arthur, W. Jr., Barrett, G. V., Alexander, R. A. (1991). Prediction of vehicular accident involvement: A meta-analysis. Human Performance, 4, 89-105.

Baldwin, C. L. (2009). Individual differences in navigational strategy: implications for display design. Theoretical Issues in Ergonomics Science, 10, 443-458.

DOI: 10.1080/14639220903106379

Barraclough, P., af Wåhlberg, A. E., Freeman, J., Watson, B., \& Watson, A. (2016). Predicting crashes using traffic offences. A Meta-Analysis that examines potential bias between self-report and archival data. PLOS ONE.

http://dx.doi.org/10.1371/journal.pone.0153390

Bioulac, S., Franchi, J.-A., Arnaud, M., Sagaspe, P., Morre, N., Salvo, F., \& Philip, P. (2017). Risk of motor vehicle accidents related to sleepiness at the wheel: a systematic review and meta-analysis. Sleep, 40, zsx 134.

https://doi.org/10.1093/sleep/zsx134 
Blom, D. H., Pokorny, M. L., \& van Leeuwen, P. (1987). The role of age and experience in bus drivers' accidents. International Journal of Epidemiology, 16, 35-43.

Burg, A. (1970). The stability of driving record over time. Accident Analysis and Prevention, 2, 57-65.

Cantor, D. E., Corsi, T. M., Grimm, C. M., \& Özpolat, K. (2010). A driver focused truck crash prediction model. Transportation Research Part E, 46, 683-692.

Carr, B. R. (1969). A statistical analysis of rural Ontario traffic accidents using induced exposure data. Accident Analysis and Prevention, 5, 343-357.

Chandraratna, S. K. (2004). Crash Involvement Potential for Drivers with Multiple Crashes. Doctoral thesis, University of Kentucky.

Chipman, M. L., MacGregor, C. G., Smiley, A. M., \& Lee-Gosselin, M. (1992). Time vs. distance as measures of exposure in driving surveys. Accident Analysis and Prevention, $24,679-684$.

Chipman, M. L., MacGregor, C. G., Smiley, A. M., \& Lee-Gosselin, M. (1993). The role of exposure in comparisons of crash risk among different drivers and driving environments. Accident Analysis and Prevention, 25, 207-211.

Clarke, D. D., Ward, P. J., Bartle, C., \& Truman, W. (2006). Young driver accidents in the UK: The influence of age, experience, and time of day. Accident Analysis and Prevention, 38, 871-878.

Cornwall, C. J. (1962). The accident experience of London bus drivers. Annuals of Occupational Hygiene, 5, 69-82.

Dorn, L., \& af Wåhlberg, A. E. (2008). Work related road safety: An analysis based on UK bus driver performance. Risk Analysis: An International Journal, 28, 25-35.

Dorn, L., \& af Wåhlberg, A. E. (submitted). Accident proneness of bus drivers; controlling for exposure.

Dorn, L., \& af Wåhlberg, A. E. (2018). Behavioural culpability for traffic accidents. Transportation Research Part F: Traffic Psychology and Behaviour, 60, 505-514. https://doi.org/10.1016/j.trf.2018.11.004

Elliott, M. R., Waller, P. F., Raghunathan, T. E., \& Shope, J. T. (2001). Predicting offences and crashes from young drivers' offence and crash histories. Journal of Crash Prevention and Injury Control, 2, 167-178. 
Elliott, M. R., Waller, P. F., Raghunathan, T. E., Shope, J. T., \& Little, R. J. (2000). Persistence of violation and crash behavior over time. Journal of Safety Research, 31, 229-242.

Greenwood, M., \& Woods, H. M. (1919). The Incidence of Industrial Accidents upon Individuals with Specific Reference to Multiple Accidents. Industrial Fatigue Research Board, Report No 4. London: His Majesty's Stationary Office.

Haight, F. A. (1973). Induced exposure. Accident Analysis and Prevention, 5, 111-126.

Harrington, D. M. (1972). The young driver follow-up study: An evaluation of the role of human factors in the first four years of driving. Accident Analysis and Prevention, 4, 191240.

Häkkinen, S. (1958). Traffic Accidents and Driver Characteristics. Unpublished doctoral dissertation, Finland's Institute of Technology, Finland.

Kaneko, T., \& Jovanis, P. P. (1992). Multiday driving patterns and motor carrier accident risk: A disaggregate analysis. Accident Analysis and Prevention, 24, 437-456.

Klauer, S. G., Dingus, T. A., Neale, V. L., Sudweeks, J. D., \& Ramsey, D. J. (2009). Comparing Real-World Behaviors of Drivers with High versus Low Rates of Crashes and Near-Crashes. US Department of Transportation, National Highway Traffic Safety Administration, Report DOT HS 811091.

Liddell, F. D. (1982). Motor vehicle accidents (1973-6) in a cohort of Montreal drivers. Journal of Epidemiology and Community Health, 36, 140-145.

Ma, M., Yan, X., Huang, H., \& Abdel-Aty, M. (2010). Occupational driver safety of public transportation: Risk perception, attitudes, and driving behavior. Proceedings of the Transportation Research Board 89th Annual Meeting (TRB 10-0600). Washington D.C. Retrieved 2018-08-20 from

http://citeseerx.ist.psu.edu/viewdoc/summary?doi=10.1.1.473.1123

Matthews, G., \& Campbell, S. E. (2009). Sustained performance under overload: personality and individual differences in stress and coping. Theoretical Issues in Ergonomics Science, 10, 417-442. doi: 10.1080/14639220903106395

Maycock, G. (1985). Accident liability and human factors-researching the relationship. Traffic Engineering and Control, 26, 330-335.

Maycock, G. (1995). Driver Sleepiness as a Factor in Car and HGV Accidents. TRL Report 169. Crowthorne: Transport Research Laboratory. 
McCartt, A. T., Shabanova, V. I., \& Leaf, W. A. (2003). Driving experience, crashes and traffic citations of teenage beginning drivers. Accident Analysis and Prevention, 35, 311 320.

McKenna, F. P. (1983). Accident proneness: A conceptual analysis. Accident Analysis and Prevention, 15, 65-71.

McKenna, F. P., Duncan, J., \& Brown, I. D. (1986). Cognitive abilities and safety on the road: a re-examination of individual differences in dichotic listening and search for embedded figures. Ergonomics, 29, 649-663.

Milosevic, S., \& Vucinic, S. (1975). Statistical study of tram drivers' accidents. Accident Analysis and Prevention, 7, 1-7.

Peck, R. C. (1993). The identification of multiple accident correlates in high risk drivers with specific emphasis on the role of age, experience and prior traffic violation frequency. Alcohol, Drugs and Driving, 9, 145-166.

Smith, L., \& Iskra-Golec, I. (2003). Internal locus of control and shiftwork effects. Theoretical Issues in Ergonomics Science, 4, 327-339.

Stewart, R. J., \& Campbell, B. J. (1972). The Statistical Association Between Past and Future Accidents and Violations. University of North Carolina: Chapel Hill.

Summala, H., Rajalin, S., \& Radun, I. (2014). Risky driving and recorded driving offences: A 24-year follow-up study. Accident Analysis and Prevention, 73, 27-33.

Szalma, J. L. (2009). Individual differences: incorporating human variation into human factors/ergonomics research and practice. Theoretical Issues in Ergonomics Science, 10, 377-379. doi: $\underline{10.1080 / 14639220903106361}$

Thoroman, B., Goode, N., \& Salmon, P. (2018) System thinking applied to near misses: a review of industry-wide near miss reporting systems. Theoretical Issues in Ergonomics Science, 19, 712-737. DOI: 10.1080/1463922X.2018.1484527

Vaa, T. (2003). Impairments, Diseases, Age and Their Relative Risks of Accident Involvement: Results from Meta-Analysis. TØI report 690/2003.

Visser, E., Pijl, Y. J., Stolk, R. P., Neeleman, J., \& Rosmalen, J. G. (2007). Accident proneness, does it exist? A review and meta-analysis. Accident Analysis and Prevention, 39, 556-564.

de Winter, J. C. (2014). Why peron models are important for human factors science. Theoretical Issues in Ergonomics Science, 15, 595-614. 
Wundersitz, L. N. (2008). Can personality characteristics predict the crash involvement of young drivers? Proceedings of the 2008 Australasian Road Safety Research, Policing and Education Conference, 9-12 November, 2008: pp. 104-113.

af Wåhlberg, A. E. (2002a). Characteristics of low speed accidents with buses in public transport. Accident Analysis and Prevention, 34, 637-647.

af Wåhlberg, A. E. (2002b). On the validity of self-reported traffic accident data. E140 Proceedings of Soric'02. Available at www.psyk.uu.se/hemsidor/busdriver/index.htm

af Wåhlberg, A. E. (2003). Some methodological deficiencies in studies on traffic accident predictors. Accident Analysis and Prevention, 35, 473-486.

af Wåhlberg, A. E. (2004). Characteristics of low speed accidents with buses in public transport. Part II. Accident Analysis and Prevention, 36, 63-71.

af Wåhlberg, A. E. (2009). Driver Behaviour and Accident Research Methodology; Unresolved Problems. Farnham: Ashgate.

af Wåhlberg, A. E. (2010). A reporting guide for studies on individual differences in safety. Journal of Safety Research, 41, 381-383.

doi: 10.1016/j.jsr.2010.05.004.

af Wåhlberg, A. E. (2011). The accident-exposure association: Self-reported versus recorded collisions. Journal of Safety Research, 42, 143-146.

http://dx.doi.org/10.1016/j.jsr.2011.01.007

af Wåhlberg, A. E. (2018). The effect of driver improvement interventions on crash involvement; has it been under-estimated? Transportation Research Part F: Traffic Psychology and Behaviour, 54, 349-356.

af Wåhlberg, A. E., Barraclough, P., \& Freeman, J. (2016). Personality versus traffic accidents; meta-analysis of real and method effects. Transportation Research Part F: Traffic Psychology and Behaviour, 44, 90-104.

http://dx.doi.org/10.1016/j.trf.2016.10.009

af Wåhlberg, A. E., \& Dorn, L. (2007). Culpable versus non-culpable traffic accidents; what is wrong with this picture? Journal of Safety Research, 38, 453-459.

af Wåhlberg, A. E., \& Dorn, L. (2009). Bus driver accident record; the return of accident proneness. Theoretical Issues in Ergonomics Science, 10, 77-91.

http://dx.doi.org/10.1080/14639220801912597 
2019-05-28

\title{
Bus driver accident record; stability over time, exposure and culpability
}

\author{
af Wåhlberg, Anders E.
}

Taylor \& Francis

AF Wåhlberg A, Dorn L. (2019) Bus driver accident record; stability over time, exposure and culpability. Theoretical Issues in Ergonomics Science, Volume 20, Issue 5, 2019, pp. 590-602 https://doi.org/10.1080/1463922X.2019.1605629

Downloaded from Cranfield Library Services E-Repository 